\title{
La violencia y la palabra. Reflexiones en torno a la obra de Emanuele Severino
}

\section{(Violence and language. Reflections on Emanuele Severino's work)}

\author{
Vicente ORDÓÑEZ RoIG \\ Universidad Jaime I \\ vordonez@fis.uji.es
}

Recibido: 5 de abril de 2011

Aceptado: 7 de septiembre de 2011

\section{Resumen}

El autor examina en el presente artículo un problema básico de la metafísica de Emanuele Severino: la posible conexión intrínseca entre la violencia y el lenguaje. Tomando en consideración diversos aspectos de su obra, se hace especial hincapié en conceptos fundamentales como el de voluntad de poder; la metafísica entendida como el espacio desde el que se articula el nihilismo; la palabra de Platón que pone a la cosa como un epamphoterizein; etc. El autor concluye que en el pensamiento de Severino la violencia y la palabra se confunden en el substrato común desde el que se alza la civilización Occidental.

Palabras clave: nihilismo, metafísica, interpretación, poder, persuasión

\begin{abstract}
The author examines thoroughly a basic problem of Emanuele Severino metaphysics: the implicit connection between violence and language. He analyzes several important distinctions, but he specially emphasizes the main aspects of his work, such as the will to power, the metaphysics as place of nihilism or the Plato's word that takes to the light the sense of the thing on having put it as an epamphoterizein. The author concludes that in Severino's thought violence and language are mixed up in the common substratum from which our civilization rises.
\end{abstract}

Keywords: nihilism, metaphysics, interpretation, power, conviction 
El pasado 28 de octubre de 2010, el New York Times publicaba un artículo de opinión de Jürgen Habermas titulado «Leadership and Leitkultur» en el que, entre otros temas, el pensador alemán se interesa por los disturbios que el proyecto Stuttgart 21 está provocando en la capital del estado de Baden-Württemberg. Habermas se pregunta: «la participación en los procedimientos democráticos, ¿tiene sólo el sentido funcional de hacer callar a una minoría derrotada, o tiene el sentido deliberativo de la inclusión de los argumentos de los ciudadanos en el proceso democrático de formación de opinión $\mathrm{y}<$ formación de la $>$ voluntad? [does participation in democratic procedures have only the functional meaning of silencing a defeated minority, or does it have the deliberative meaning of including the arguments of citizens in the democratic process of opinion- and will-formation?]». La cuestión es relevante porque la actitud represiva de las fuerzas de orden público atenta contra la racionalidad de las prácticas que en democracia deben buscar el entendimiento: al constreñir a una minoría al silencio se revocan las acciones comunicativas que posibilitan el consenso, impidiendo la «cancelación de aquellas relaciones de violencia que se han acomodado inadvertidamente en las estructuras comunicacionales» (Habermas 1983, p. 34). Frente a la reciprocidad de las normas de validez intersubjetiva, la unilateralidad de la coerción y la fuerza. El 15 de noviembre aparecía en el berlinés Die Tageszeitung otro artículo -«Die Arroganz der Macht»- en el que Georg Seesslen, a propósito de la represión policial contra los manifestantes del Stuttgart 21, reflexiona sobre las relaciones entre violencia, poder y democracia, y concluye que «la violencia todavía juega un papel central en la intimidación de los ciudadanos [nach wie vor spielt die Gewalt bei der Einschüchterung der Bürger und Bürgerinnen eine Schlüsselrolle]». Naturalmente, la violencia no es un fenómeno exclusivo de la democracia alemana: la carga de lo que Guy Debord llama le serviteur actif de la marchandise, esto es, la puesta en marcha de la maquinaria policial contra manifestantes que exigen, reivindican, se oponen, protestan, etc., es lugar común en las sociedades occidentales contemporáneas. Ya Spinoza señala en su Tratatdo teológico-político que el Estado violento por excelencia es aquel que niega a cada uno la libertad de decir y manifestar lo que piensa: «illud ergo imperium violentissimum erit, ubi unicuique libertas dicendi et docendi quce sentit negatur» (Spinoza 1882, p. 603). Y es que el Estado no sólo puede intimidar y disuadir, sino también persuadir de la legitimidad del uso de la fuerza: no en vano, es el Estado la fuente de la que mana el derecho a la violencia1.

\footnotetext{
1 Cf. Hobbes (1989, p. 151): «al soberano le corresponde el poder de premiar con riquezas u honor, y de castigar con penas corporales o pecuniarias, o con ignominia, a todo súbdito suyo, de acuerdo con la ley que haya sido previamente establecida; y si no se ha hecho ninguna ley, actuará como le parezca más conveniente para dar a los hombres un incentivo que los haga servir al Estado, o para disuadirlos de que dañen al mismo»; Weber (1996, p. 84): «el Estado es la única fuente del "derecho" a la violencia»; Schmitt (1991, p. 74): «al Estado, en su condición de unidad esencialmente política, le es atribución inherente el ius belli»; Bourdieu (1980, p. 218) : «esta coexistencia de la violencia abierta,
} 
Ahora bien, ¿es la instrumentalización de la violencia, entendida como control social, el único medio del que dispone el Estado para acallar las reacciones colectivas? ¿Acaso no debe un Estado democrático moderno recorrer hasta el final las vías del lenguaje: deliberación, reunión, debate, diálogo, etc.? ¿O es que quizá esas mismas vías lingüísticas están emparentadas genéticamente con la violencia? ¿Es el lenguaje, no sólo instrumento comunicativo, sino también artefacto nihilizador? Algunas de estas cuestiones surgen cíclicamente en la obra del pensador italiano Emanuele Severino. Intentaremos acotarlas con el objetivo de determinar si la relación entre violencia y lenguaje es endogámica o si, por el contrario, son dos ámbitos que solamente a posteriori tienen algún vínculo entre sí.

\section{Los dos timbres}

Severino se pregunta si en las raíces del modo de pensar de nuestra civilización «no anida una violencia enorme, muy superior a aquella que, terrible, hemos experimentado en nuestra historia [non si annidi una violenza immane, ben superiore a quelle, terribili, che habiamo sperimentato nella nostra storia]» (Severino 2000, p. 17). Esclarecer este punto implica, según el pensador italiano, atender a las fuentes de las que brotan las lenguas griega y latina, que son, a su vez, el terreno en el que crece el lenguaje de Occidente.

Las lenguas griega y latina pertenecen al grupo de lenguas o familias de lenguas que tienen su origen en el indoeuropeo, la forma más antigua del lenguaje de la que provienen casi todas las lenguas de la civilización occidental. En Destino della necessità, Il parricidio mancato y Oltrepassare, Severino indica que en la lengua indoeuropea resuenan dos timbres contrastantes y antagónicos que el hombre de nuestros orígenes cree ver en el mundo: el timbre de la flexión y el timbre de la inflexión. El significado de la mayor parte de las raíces de los nombres indoeuropeos construidos a partir de una consonante líquida $(1, r)$ prueba la acción de la potencia capaz de modificar el mundo, de hacer que las cosas se conviertan en lo otro de lo que son, de doblegarlas. Es el timbre de lo flexible². Lo flexible es flexum: un doblar y un plegar en el que se refleja la voluntad de imprimir una cierta dirección, una dirección determinada, a una cosa. Por eso no se dobla sólo una rama, o las

física o económica y de la violencia simbólica más refinada, se encuentra en todas las instituciones características de esa economía y en el núcleo mismo de cada relación social»; etc. Platón, por otra parte, justifica al político que, como el médico o el piloto de una nave, impone por la fuerza lo que es mejor (Político 296 b).

2 Platón avanza en el Crátilo la hipótesis de que la consonante líquida $\rho$ sea «el instrumento de todo "movimiento"» (426 c), el medio adecuado con el cual el arte de dar nombres nombra el devenir -y la consonante $\lambda$ es entendida como el indicador de ese tipo de transformación que es el «resbalar»o el «deslizarse» $(427 \mathrm{~b})$. 
rodillas, o se encorva la espalda, sino también se aparta a uno de su propósito o se le ablanda (a través del discurso, por ejemplo), se modula la voz, se mueven las mentes y las almas, etc. Por otro lado, el significado de la mayor parte de las raíces indoeuropeas construidas sobre una consonante oclusiva (p, b, t, d, k, g...) o fricativa (s, z...), nombran el obstáculo, la resistencia que se halla presente por la acción de aquella potencia que el artífice advierte como insuperable: es el timbre de lo inflexible, de aquello frente a lo cual el hombre se siente impotente. Lo inflexible es lo indomeñable, lo inmutable o inmodificable: «lo inflexible es aquello que hombres y dioses todavía no pueden doblar [l'inflessibile è ciò che uomini e dèi non riescono ancora a flettere]» (Severino 2007, p. 49). La lengua indoeuropea atestigua, según Severino, la tensión ambivalente que late en el lenguaje de Occidente: lo flexible, aquello que por su disponibilidad cae en el dominio de la acción, convirtiéndose en el material o en el objeto de la misma; lo inflexible: la barrera insuperable que ni se pliega a la voluntad humana, ni cede al capricho de los inmortales.

El irrumpir de la acción del hombre es la primera tentativa de destrucción del ámbito de lo inflexible. Si el contraste entre la flexión y lo inflexible se refleja en la lengua de la prehistoria de Occidente como contraste entre el timbre de la flexión y el timbre de lo inflexible, el contraste entre los dos timbres constituye el modo específico en el que la destrucción de lo inmodificable, de lo inmutable, acaece en la lengua que se prepara para acoger el lenguaje de Occidente. Pero, ¿cómo se expresa en la lengua esta violencia contra el inflexible acaecer del mundo? ¿Con qué instrumentos puede derribar el hombre aquello que se presenta como inviolable?

El timbre de la flexión puede rastrearse en un grupo de palabras de las lenguas griega y latina y de todas las lenguas indoeuropeas que, construidas a partir de las raíces ar, dhreugh, lei, leubh, uel, etc., nombran la estructura formal de la acción. El área semántica de ar, por ejemplo, es vastísima. Pensemos en ars, que inicialmente traducimos por arte: aquella disposición en la que las cosas aparecen conectadas y ordenadas con vistas a la consecución de un objetivo determinado. Al servirse de las cosas, los humanos las convierten en medios, en instrumentos con los que lograr aquello que se proponen. Por eso ars es artus (á $\rho \theta \rho o v$, articulación). «Artus no es simplemente aquello que está unido al cuerpo, sino el instrumento originario del que el mortal se siente dueño y que le permite modificar el mundo en el que vive [Artus non è semplicemente ciò che è unito al corpo, ma è lo strumento originario di cui il mortale si sente padrone e che gli consente di modificare il

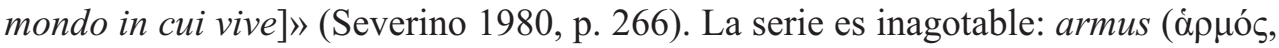

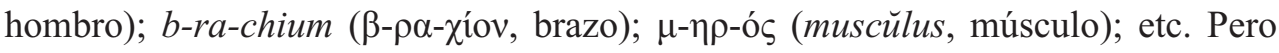
también ar-ma (ó $\rho-\mu \varepsilon v \alpha$ ), el estar provisto de algo, de un instrumento (de un escudo o de una lanza), instrumento que es ya un ő $\rho-\gamma \alpha v o v$. El ser humano que actúa, que se sirve de la cosa como instrumento de la acción, se siente su dueño y señor.

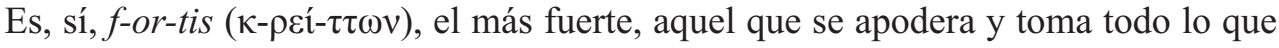


quiere. «La f-or-tuna ( $f$-or-s; sánscrito $c ̧$-rí-s) es el adaptarse las cosas a la fuerza del fortis y, al mismo tiempo, es la fuerza de la obra insondable de los dioses (y $g$ -

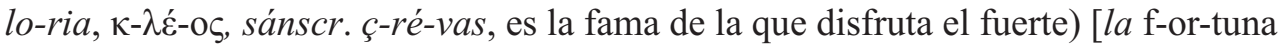
(f-or-s; sanscrito ç-rí-s) è l'adattarsi delle cose a la forza del fortis e insieme è la forza dell'arte insondabile dei divini (e g-lo-ria, $\kappa-\lambda \varepsilon \dot{\varepsilon}-\mathrm{o}$, sanscr. ç-ré-vas, è la fama goduta dal forte)]» (Severino 1980, p. 266). También la palabra (v-er-bum, $\rho \eta ́-\mu \alpha)$ es un instrumento, instrumento a través del cual el ser humano conquista aquello que codicia. Para ello debe predisponer a la cosa o a la entidad que quiere obtener; esto es, debe prever la cosa de la que quiere arrogarse o disponer anticipadamente de su ánimo para lograr por medio de la palabra aquello que anhela. Por eso la lengua griega nombra a los mortales de dos formas: de un lado, $\beta$ - $\rho$ - $\tau$ ó $\varsigma$ designa al mortal entendido como ar-tifex; de otro, $\mu$-غ́ $\rho-o \psi$ (de voz articulada o dotado de habla) se hace eco de lo más preciado que obtiene el mortal con su acción: la palabra $(\dot{\eta}$ ö $\psi)$.

El ser humano logra transformar los obstáculos que en principio se presentan como insalvables gracias a dos acciones estrechamente vinculadas entre sí: como artífice, el hombre se apropia del mundo por mediación de un arte o una técnica con la que logra dominar la totalidad de lo existente. Como ser lingüístico, el hombre cree dominar y producir la totalidad de lo existente por medio de un instrumento extraordinario: la palabra. Donde la rigidez de lo inflexible no se puede disolver, los distintos instrumentos al alcance del hombre hacen posible el doblar y el plegar y, por tanto, el destruir la barrera infranqueable de lo inmutable. El que en la lengua indoeuropea y en las lenguas griega y latina se refleje la estructura formal de la acción es ya un modo de la destrucción de lo inflexible en la prehistoria de Occidente y, por consiguiente, un modo primitivo de violencia.

\section{La palabra como instrumento}

Es Platón el primero en destacar el carácter orgánico o instrumental de la palabra: la palabra es un instrumento diseñado por el legislador en el ámbito de la lengua (Crátilo 388 a). El «arte del legislador», escribe Proclo en su comentario al Crátilo, «fundamenta los nombres como estatuas de las cosas» (Proclo 1999, LI p. 87). Los nombres que se erigen incólumes como estatuas consiguen fijar por convención, no por naturaleza, el ser de la cosa. Es por esto que Platón sostiene que el legislador es dueño de los nombres, y lo es en virtud de su palabra: al dar el nombre, el legislador se convierte en «dador de nombres» o «nominador» (Crat. 389 a), aquel que sabe aplicar a los sonidos y sílabas el nombre adecuado para cada objeto. Por eso la acción de dar nombres no está al alcance de cualquiera: el que impone un nombre mediante la palabra es aquel que conoce las reglas y normas por las 
que un nombre es constante e invariablemente lo que es ${ }^{3}$. Porque suya es la técni$c a$ de establecer nombres, el legislador es el forjador de las denominaciones. «Es obvio que tal como juzgaba las cosas el primero que impuso los nombres, así impuso éstos» (Crat. 436 b). Interesa resaltar aquí el verbo empleado por Platón, $\tau i ́ \theta \eta \mu 1:$ aquel que pone el nombre determina, establece e instituye a través de la palabra. Determina cómo hay que referirse a la cosa por él nombrada; establece, por tanto, el uso correcto que, a partir de entonces, queda fijado o instituido. Por eso el que pone los nombres impone, esto es, hace valer su autoridad al marcar la dirección que desde ese instante debe seguir quien haga uso del nombre.

Poner el nombre es forzar al otro a cargar con la obligación de emplear ese nombre de un modo preciso. La desviación no debe permitirse bajo ningún concepto. Es en este sentido que Kant, en el libro primero de la Dialéctica trascendental de la Crítica de la razón pura, explica que forjar nuevas palabras es una insolencia y una usurpación, además de una actitud petulante de quien así actúa, en tanto que lo que se persigue es nada más y nada menos que legislar en el ámbito del lenguaje: «neue Worten zu schmieden, ist eine Anmaßung zum Gesetzgeben in Sprachen» (B 369). Kant emplea, no por casualidad, el verbo schmieden, «forjar», «fraguar», «martillar». Schmied es en alemán el herrero, aquel que en su origen trabaja el bronce. El herrero que trabaja el bronce lo hace con instrumentos afilados sin cuya ayuda no podría tallar, esculpir o celar esa cosa en la que ocupa su tiempo -no podría, por tanto, cortar con un buril o cinceles metales para darles alguna forma o esculpir con cualquiera de ellos lo que fuere. También quien forja palabras hace una incisión en lo real con vistas a extraer de ese material heterogéneo y polifónico elementos específicos con los que recoger, ordenar, reunir, legislar. Su acción violenta (y arrogante) permite, sin embargo, habitar en el mundo con los instrumentos de la lengua.

En el Crátilo, no obstante, emplear el nombre como instrumento lleva aparejada una acción doble: de un lado, uno enseña algo al otro o le instruye en el modo de hacer algo. Al mismo tiempo, al nombrar con el nombre en calidad de instrumento, Platón señala que efectuamos una acción muy concreta: «distinguimos las cosas» (388 b), esto es: uno descompone en sus elementos simples todo aquello con lo que tiene que vérselas en la práctica, lo que le permite no sólo enseñar o instruir, sino también y sobre todo distinguir la esencia de las cosas que le vienen descubiertas en la práctica. Así como la lanzadera es el instrumento por medio del cual se separa la trama de la urdimbre cuando se hallan entremezcladas, el nombre es el instrumento que permite al ser humano conocer, ordenar su pensamiento $\mathrm{y}$, en defini-

\footnotetext{
3 Platón señala que el legislador en materia lingüística es un artesano o demiurgo muy raro de ver: como demiurgo, el legislador debe construir los nombres bajo la supervisión del dialéctico, que es quien sabe preguntar y responder con palabras, sirviéndose de ellas ajustada y correctamente (Crat. 390 c). Platón pone por encima del legislador al dialéctico: éste, que usa y se sirve de los nombres, tiene mayor peso en materia lingüística que el legislador.
} 
tiva, saber lo que las cosas son. Severino advierte que el término $\pi-\rho \tilde{\alpha}-\gamma \mu \alpha$, la cosa, es una suerte de metátesis de $\dot{\alpha} \rho \pi \alpha \gamma$ (la acción de coger o arrebatar y que, por ello, se traduce también por "rapiña" o "saqueo") o de $\alpha \rho \tau \alpha \xi$ ("ladrón", "bandido").

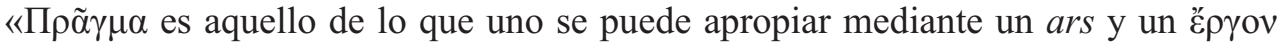

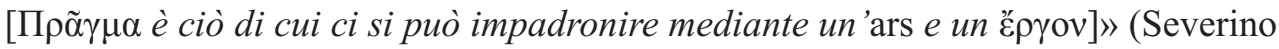
1980, p. 275). Si es posible distinguir la esencia de las cosas es porque, previamente, las cosas han sido conquistadas por la acción del hombre. Y la acción que gana para sí la cosa no puede ocultar la violencia que queda grabada en el vehículo de la difusión de la acción que es el lenguaje de Occidente. «La acción de la civilización occidental es una acción violenta. Una enorme masa de acciones violentas. Se reproduce entre los Estados, y entre los individuos, y en el interior del individuo mismo [l'agire de la civiltà occidentale è un agire violento. Una enorme massa di azione violente. Nei rapporti tra gli Stati, e tra gli individui, e all'interno dell'individuo stesso]» (Severino 2006, p. 153). La palabra que dice la cosa por razón del nombre es, de este modo, aquello que se obtiene porque uno lo reclama como suyo: la voluntad que se enseñorea de la cosa la arrebata con violencia de su quicio natural y la utiliza en aquello que considera necesario.

\section{Fe en el devenir}

La palabra aislada, sin embargo, no es todavía algo. En el Sofista explica Platón que el género que hace posible que el ser sea manifiesto es doble: «uno se llama nombre; el otro verbo» (Soph. 262 a). Para que haya lenguaje, discurso, logos, se necesita eso que, en La struttura originaria, Severino denomina «dualità unificata»: la conexión entre un verbo que muestre las acciones y un nombre que sea aplicado al agente que lleva a cabo la acción. El lenguaje es ontológicamente ambiguo: únicamente en virtud de la síntesis que aglutina una cosa y una acción mediante un nombre y un verbo hay discurso. Ahora bien, Aristóteles muestra que el verbo, signo de lo que se atribuye a un sujeto, es fundamentalmente tiempo ( $D e$ Interpretatione $16 \mathrm{~b}$ 6). Poner la palabra en el tiempo, entonces, equivale a conectarla con lo que es, era o será, con aquello que deviene. Por eso el verbo provoca en el usuario de la lengua la ilusión de alterar la realidad, de transformarla o sustituirla. También el nombre paraliza y retiene, abstrae las cualidades de la cosa para considerarla aisladamente. El verbo y el nombre anonadan: si el logos acaece en el tiempo y el tiempo es un debatirse entre lo que ha acontecido -y, por ende, ya no es-, y lo por venir -lo que todavía no es (Aristóteles Física 217 b 33-34)-, en el mismo seno del logos se evidencia la nihilidad del lenguaje. Porque el logos es el decir que lleva al lenguaje lo que aparece. Y lo que aparece es aquello que el lenguaje hace comparecer en su trayecto de la nada - de donde sale-a la nada -a donde 
retorna-. De ahí que Severino considere que el lenguaje que parte de Platón y Aristóteles (el lenguaje metafísico que con Hegel llega a su maximum) no es sino el punto arquimédico desde el que se articula la historia del nihilismo: «ello significa que el lenguaje metafísico habla de la nihilidad del ente, pero habla desde el interior del límite último consentido a su hablar, esto es, desde el interior del límite sobrepasando el cual, el lenguaje metafísico expresa la propia alienación [ciò significa che il linguaggio metafisico parla della nientità dell'ente, ma ne parla all'interno del limite estremo consentito al suo parlare, all'interno cioè del limite, oltrepassando il quale, il linguaggio metafisico direbbe la propria alienazione]» (Severino 1980, p. 425).

Inicialmente el logos reúne lo disperso y deja atado lo que, de no mediar él mismo, tendería irremediablemente a desaparecer. Al igual que Isis reconstruye los disjecta membra de un Osiris brutalmente despedazado, el logos salva en ese reunir lo que de otro modo se destruiría sin remedio, disgregándose y diluyéndose en el insondable abismo de lo indeterminado. Severino explica que «cuando la palabra légo (que significa precisamente "reúno", "pongo junto") se usó en la lengua griega en sentido metafórico para designar el decir, el hablar, el lenguaje realizó una grandiosa reflexión sobre sí mismo y se vio como lo que reúne en sí el entero universo» (Severino 1991, p. 175). Que el logos reúna lo que deviene supone que en la estructura que sirve de sustrato a la civilización occidental se acepta tácitamente que las cosas son y dejan de ser. El terreno desde el que brota el lenguaje de Occidente es la lengua griega. Y es en el interior de la lengua griega donde se expresa lo que hasta ese momento no se ha oído nunca: que la cosa, en tanto que ente, deviene, es y no es, oscila entre el ser y la nada. La existencia del devenir muestra que las cosas, que son no-nada, se vuelven su contrario en virtud de esta convicción incontrovertible. Sin embargo, ¿cómo es posible que las cosas sean algo y sean nada si, forzosamente, el no-ser no puede bajo ningún concepto entenderse como algo?

El devenir es la evidencia originaria, la intuición de que todo ente se genera y se destruye, es y no es, y que, como tal, puede ser no sólo aniquilado, sino también creado. Con el fin de captar correctamente la oscilación entre el ser y la nada,

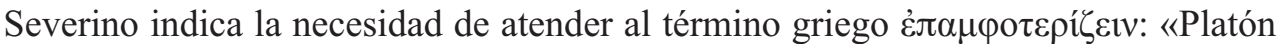
lleva a la luz el sentido de la cosa -el horizonte en cuyo interior crece la historia

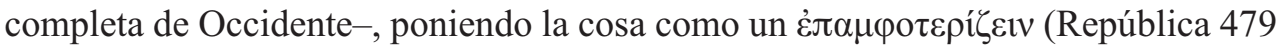

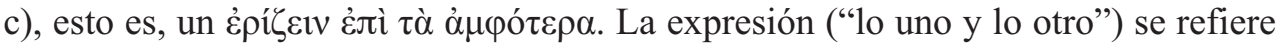
al ser y a la nada. La cosa es el "debatirse entre lo uno y lo otro" [Platone porta alla luce il senso della cosa -l'orizzonte al cui interno cresce l'intera storia

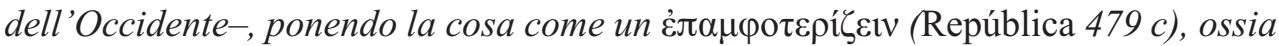

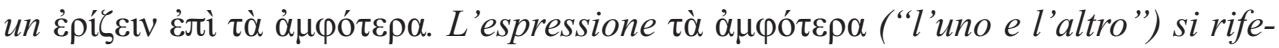
risce all'essere e al niente. La cosa è il "dibattersi tra l'uno e l'altro"]) (Severino 1980, p. 21). Que la cosa sea un «debatirse entre lo uno y lo otro» quiere decir que en el ente, entendido como la cosa que oscila entre el ser y la nada, palpita la alie- 
nación extrema y la locura de Occidente: la convicción de que cada ente es fatalmente arrojado al orden alternativo o sucesivo del nacimiento y de la muerte. La lengua griega es el testimonio, en la apertura del espacio ontológico, del agitarse los entes en ese modo fluctuante o intermedio. Ese testimonio muestra la vocación fundacional del lenguaje de Occidente: su voluntad de nada. Porque si el ser es algo que proviene de la nada y que, inexorablemente, se dirige a ella, es la nada la que conforma la esencia de Occidente. Occidente quiere que las cosas sean tiempo, historia, transformación, devenir, un surgir de y un retornar a algo. Pero el tiempo y la historia occidentales son tiempo e historia, transformación y devenir no de algo, sino de nada -podríamos parafrasear a Miguel de Molinos diciendo que el devenir es este mismo proceso en el que el ente halla una puerta para entrarse en su nada, conociendo que es nada, que puede nada-. En el seno de la lengua griega y, concretamente, a partir de la metafísica platónica, se fragua la fe en el devenir -si bien la palabra de Platón envuelve en la oscuridad de lo que se dice indirectamente: la palabra que afirma el oscilar del ente no dice que el ente sea nada; pero que el ente se determine por la oscilación prueba que su relación con el ser es algo meramente accidental. De todo ello se sigue que el ente es disponibilidad para la nada; y si el ente es disponibilidad para la nada, resulta que «el ente (y por consiguiente, también el hombre) está destinado a la manipulación, a la violación, a la explotación por obra de los dioses, de los amos y de la técnica [l'ente (e quindi anche l'uomo) è destinato alla manipolazione, alla violazione, allo sfruttamento per opera degli dèi, dei padroni e delle tecniche]» (Severino 1981, p. 33). El resultado final de la apuesta por el devenir que se inicia con el lenguaje de la metafísica occidental la explica Severino en términos de manipulación, violación y explotación del ente. No es, como sostiene Nietzsche, que el hombre prefiera creer en la nada a no creer: es que en el inconsciente de Occidente reverbera la persuasión de que el mismo ente es ya nada. Quizá sea Hegel quien mejor resume la fe que Occidente tiene depositada en el devenir: «el devenir es la verdadera expresión del resultado del ser y de la nada, en tanto es su unidad; y no es sólo la unidad del ser y la nada, sino < la unidad $>$ que es en sí misma inquietud, agitación, movimiento» (Hegel 1970, p. 190). Lo que el pensamiento ha silenciado, sin embargo, es que ese movimiento unificador en el que el ente se tambalea entre el ser y la nada produce la enajenación del hombre occidental: si el ente es creación desde la nada a la cual retorna cuando es fatalmente destruido, las ligaduras que necesariamente tienen al ente ligado al ser se sueltan $-\mathrm{y}$ este soltarse las ligaduras del ser es, precisamente, lo que desde Anaximandro hasta Parménides no debe acontecer bajo ningún concepto. A partir de la metafísica griega, el devenir otro por parte de algo es la aniquilación de algo en tanto que idéntico a sí y es el salir de la no-nada por parte del otro, con el que algo se identifica. «Sobre esta identificación del ser y de la nada se funda la historia de Occidente. Que, por lo tanto, es la historia del nihilismo» (Severino 19912, p. 156). 


\section{Lo ilimitado}

Severino considera que la fe inquebrantable en la existencia del devenir es la forma originaria de la voluntad de dominio. Que el devenir se convierta en la razón de ser de la voluntad de dominio nos lleva a la pregunta de cómo puede la voluntad de dominio cristalizar en el lenguaje que permea la mayoría de las lenguas de la civilización occidental. Ya hemos señalado que en el lenguaje pre-metafísico occidental, la voluntad de poder aparece como la tendencia que abre la dimensión del dominio, esto es: se manifiesta como predisposición a pensar el obrar, el actuar, el hacer como dominio. Severino matiza, sin embargo, que esta tendencia sólo se confirma en la lejanía del lenguaje metafísico que forja el sentido de la cosa: «es sólo en el horizonte del lenguaje metafísico que las cosas llegan a estar disponibles ilimitadamente para ser dominadas por los mortales [è solo nell'orizzonte del linguaggio metafísico che le cose diventano ilimitatamente disponibili al dominio del mortale]» (Severino 1980, p. 264). La predisposición de las lenguas griega y latina a pensar la acción como acción instrumental provoca, por tanto, que las cosas estén disponibles para ser dominadas por los mortales. Y dominadas, aclara Severino, no de esta o de aquella manera, sino de una forma muy especial: ilimitadamente. Es Platón quien afirma que uno puede encontrar lo ilimitado por todas partes: «hay en el universo gran cantidad de ilimitado» (Filebo $30 \mathrm{c}$ ). Ilimitado es el mundo de los eventos fortuitos donde cabe ubicar el más y el menos, lo más caliente y lo más frío, lo más fuerte y lo más suave, aquello exento de proporción y mesura y que, por ello, es cuantitativamente indeterminado. Entonces: si es en el horizonte de la inestabilidad del ente que se plasma la voluntad de dominio, la palabra que afirma el devenir -la palabra que, desde Platón, afirma que la cosa es un oscilar entre el ser y la nada- es ya voluntad de dominio y, por consiguiente, fuerza, potestad, violencia. Porque si las cosas están a disposición del hombre ilimitadamente, uno puede servirse de ellas. Y no sólo servirse: allí donde hay ausencia de límite uno puede excederse con la cosa, y hacerlo desmesuradamente. Que uno pueda no sólo apropiarse y servirse, sino y sobre todo excederse con la cosa, es consecuencia directa de la disponibilidad ilimitada de la misma. Al impedir que la cosa tenga una magnitud fija, la cosa se convierte para la metafísica en aquello de lo que uno se apodera porque ella misma, la cosa, no está sino conectada con nada.

La disponibilidad ilimitada de las cosas, que son nada, hace que la acción del hombre se dirija a la producción y destrucción del ser. En el lenguaje pre-metafísico de Occidente "producción" y "destrucción" son términos sin referente: la acción del hombre no es todavía la acción que trasvasa las cosas de la nada al ser y del ser a la nada. A partir de la metafísica platónica, en cambio, no causará estupor sino, antes bien, desidia e impasibilidad, la contemplación atónita de las grandes formas de la productividad y destructividad occidentales. Que la capacidad de producción 
y destrucción de la civilización occidental no conozca límites se comprende en cuanto se atiende a la persuasión que rige el destino de Occidente: lo que es, que podría no ser - pues cabe la posibilidad de que permanezca como nada-, en poco tiempo, sin duda, dejará de ser -es decir, será aniquilado, volverá a no ser-. En varias de sus obras (Gli abitatori del tempo, Esencia del nihilismo, La tendencia fundamental de nuestro tiempo, Oltre il linguaggio, etc.) Severino advierte que esa capacidad de producir y destruir que es resultado del salir la nada del ser y de su inminente anulación, alcanza cotas insospechadas gracias a la conexión entre poder y racionalidad científica: es necesario producir artefactos cada vez más nuevos, artefactos que favorezcan un tipo de experiencia única, radical, más intensa y desconocida. De igual modo, el Apparato scientifico-tecnologico debe incrementar indefinidamente la capacidad de llevar cada vez más lejos, en tanto que la vivencia de la nada reclama la innovación periódica y la creación absoluta. Severino coloca la novedad y la lejanía en un plano ontológico: son las inesperadas categorías que se articulan a partir de las relaciones de dominio. La acción instrumental produce constantemente lo nuevo porque el ente es lo que surge de la propia nada. A su vez, la destrucción puede conducir a la extrema lejanía de lo existente porque lo existente se genera y se corrompe para volver al no-ser. «Si efectivamente el ente es lo que oscila entre ser y nada, entonces pertenece a la misma esencia del ente su ser producido, destruido, creado, aniquilado, manipulado, trasformado, devastado, controlado, dominado o explotado sin límite alguno» (Severino 19913, pp. 168-169). Después del lenguaje metafísico de Occidente el hombre adquiere la facultad de sacar las cosas de la nada y hacerlas volver a ella efectivamente, porque es en el lenguaje metafísico donde se verifica que la cosa no es sino aquello de lo que uno puede servirse ilimitadamente. El lenguaje metafísico occidental se vuelve condición de posibilidad de la existencia de la voluntad de dominio porque sólo a partir de la palabra que afirma el devenir se abre para el ser humano la perspectiva de la violencia última: puesto que la fe en el devenir entraña la creación ex nihilo y la destrucción, no sólo de todo lo inmutable, sino también de toda necesidad y de toda imposibilidad, la acción que se articula desde el lenguaje metafísico no conoce límite alguno -pues no existe, de facto, límite que no pueda ser sobrepasado. «La forma que en el pensamiento griego asume la fe en la existencia del devenir -esto es, la dimensión en la que se manifiesta toda la "historia" de Occidente- es también la forma extrema de la violencia [la forma che nel pensiero greco asume la fede nell'esistenza del divenire - cioè la dimensione in cui si manifesta l'intera "storia" dell'Occidente-è quindi anche la forma estrema della violenza]» (Severino 1992, p. 29). En tanto que apuesta, fe por la cual se cree (fides qua), la historia de Occidente $-\mathrm{y}$, por ende, no sólo la historia de la filosofía occidental- hace evidente e indubitable lo que ni es evidente ni indubitable: la persuasión de que cada ente es algo pasajero, una realidad que es expresada en un doble sentido y que hay que ubi- 
car entre el no-ser y el ser y que, por ello, sufre la disolución entre uno y otro extremo. Pero la fe por la cual se cree es, al tiempo, la fe en la que se cree (fides quae). Y la fe en la que se cree es la fe que iguala e identifica todo aquello que, siendo diferente, se presenta en el devenir, provocando que dos o más cosas de distinta naturaleza aparezcan y se consideren como una misma. La fe, con todo, es convicción, persuasión, no conocimiento - pues, ¿acaso la lengua que delinea el destino de Occidente no emplea el mismo verbo para nombrar el «persuadir» y el «seducir o

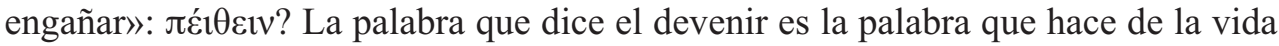
del hombre voluntad de dominio; una vida que es ßíos pero, también, ßía.

\section{Las puertas de las sendas de la Noche y el Día}

La palabra que, dejando atrás las moradas de la Noche se encamina «hacia la luz» (Parménides fr. 1 v. 10), se extravía en la palabra alienada y violenta de la metafísica occidental. Severino considera que, del mismo modo que Parménides arroja y esparce las semillas que hacen posible el sendero del Día, es el mismo Parménides el que desbroza y hace transitable el sendero de la Noche: «evocando al propio enemigo, hace ya que exista [evocando il proprio nemico, lo crede un già esistente]» (Severino 1980, p. 529). Parménides es conducido por las hijas del Sol hasta lo alto del éter, al lugar en el que se encuentran las puertas de las sendas de la Noche y el Día. Una vez traspasadas las puertas cuyas llaves custodia Justicia, es guiado hasta «la diosa». En presencia de la diosa, Parménides oye el primero de los caminos de búsqueda que cabe concebir: «el de que es y no es posible que no sea» (fr. 2 v. 3). Severino entiende que la palabra testimonial de Parménides, la palabra que escucha y que dice el no-ser para negarlo, evoca con su testimonio el no-ser. Y al evocarlo hace posible el paso que va del ser al no-ser. Aunque la oscuridad translúcida del poema preludia la revelación, Parménides no recorre la senda del no-ser: permanece en el lugar en el que las sendas de la Noche y el Día se bifurcan. El paso a través de la senda de la Noche que la palabra de Parménides hace viable es ya el paso de Platón. Platón inicia la marcha al poner como fundamento o principio, no sólo que la cosa es, sino que esa misma cosa no es (Parménides 135e-136a). Lo que el hombre occidental no ha oído ni ha visto nunca, entonces, aquello de lo que no ha sido testigo porque su trayecto es camino que conduce hacia lo totalmente insondable, completamente desconocido o inescrutable ( $\pi \alpha v \alpha \pi \varepsilon v \theta \varepsilon ́ \alpha$, Parménides fr. $2 \mathrm{v}$. 6), queda fijado por la palabra de Platón que, al contraponer el ser al no-ser, identifica el ser con el no-ser y viola el mandato que prohíbe expresamente que algo, sin ser, sea. Esta palabra es, justamente, la que ha llevado a la civilización occidental al alejamiento de la verdad del ser. El progresivo alejamiento del ser ha hecho del ser un eco lejano. Ese eco lejano, hoy prácticamente imperceptible, es el desarrollo del olvido del ser. 
El hombre ha perdido la memoria del ser. El olvido de la verdad del ser por parte del hombre, sin embargo, no debe entenderse en términos de hipostatización del ente o cosificación del ser: lo que se olvida según Severino es que el ser es lo inmutable, lo eterno o sin límite. Al olvidar la naturaleza permanente e invariable del ser, el hombre transforma la totalidad de lo existente en una región inhóspita: la tierra aislada del devenir. El olvido se convierte de este modo en un potente instrumento contra el ser, un Zwangsmittel o medio coactivo al servicio de la civilización occidental. «La cultura occidental no puede poner límite alguno a esta agresión del ente, porque la esencia de tal cultura es el nihilismo metafísico, cuya realización más radical y rigurosa es la técnica. Ya para el más antiguo pensamiento metafísico, el ser es $\tau \dot{\varepsilon} \chi v \eta »$ (Severino 19912, p. 207). La civilización de la técnica es, según Severino, la forma en la que actualmente se presenta la metafísica. La tierra, la tierra aislada desde la que germina la civilización de la técnica es, no obstante, la misma tierra que sustenta la no verdad de Occidente; esto es, la tierra que, desde Platón, hace de la totalidad de lo real potencia, fuerza, poder (Soph. 247 d-e). Porque lo que es, es lo que tiene en sí la capacidad de hacer o de ser hecho. Esa capacidad o poder constituye la esencia de la técnica. Es significativo como Platón divide ya la técnica en dos géneros o formas: una técnica productiva que permite llevar al ser lo que antes no existía, pues era nada, no-ser; una técnica adquisitiva, que es la que concierne al conocimiento, a todo aquello que se aprende -y lo que se aprende es un apresar o un capturar mediante el logos y la praxis lo que, desde la nada, ha llegado a ser (Soph. 219 a-c). Las palabras y las acciones permiten al ser humano apresar las cosas que hay en el mundo al precio de destruir, de flexionar o doblegar lo que no se deja doblegar y que, como tal, constituye lo inflexible, lo inmutable del mundo. Severino considera que, en la cultura occidental, la extensión y profundidad de la agresión contra lo inmutable no ha sido calibrado en su justa medida. «El hombre, en la actualidad, ya ha empujado al ocaso todo lo inflexible y cree que todas las cosas son objeto de su voluntad. Pero este ocaso empieza ya en el comienzo de la historia de nuestro lenguaje, cuando las mismas palabras que originariamente nombran el inviolable acaecer del mundo (...) se ven empujadas a indicar el arte, la "técnica" con la que precisamente el hombre se adueña del mundo e interpreta el mismo mundo como la obra de un arte supremo cuya clave debe descubrir» (Severino 1991, pp. 75-76). El progresivo isolamento della terra que Severino denuncia comienza con la palabra que se arroga la cosa al precio de destruir lo inmutable. Nada debe erigirse como inmutable, como totalmente incontrovertible o indomeñable porque, precisamente eso mismo inmutable, incontrovertible o indomeñable entra en conflicto con el eterno devenir de lo existente.

Occidente no comprende, sin embargo, que el ser es en sí eso mismo inmutable, incontrovertible e indomeñable. Por eso el pensador italiano defiende que no es posible doblegar lo inmutable mediante la palabra y la acción porque lo que una y 
otra creen doblegar no es sino el ser mismo. Y el ser, como inmutable, ni se genera ni se corrompe ni se desfigura ni perece nunca: todo el ser es. «La totalidad del ser (y por tanto el ser manifiesto, en cuanto es ser) en cuanto inmutable se recoge y se mantiene junto a sí, formando una dimensión diferente de la del ser en cuanto deviniente, esto es, formando ese reino hospitalario donde el ser queda custodiado para siempre y para siempre sustraído a la rapiña de la nada» (Severino 19912, p. 58). Todo lo que es, está desde siempre a salvo en el sitio de acogida, en el lugar para su cuidado que es el círculo inmutable del ser. El círculo inmutable del ser se construye sobre dos principios fundamentales: el primero afirma que la totalidad del ser, el ser en sentido absoluto, no está sujeto a la zozobra del devenir: «el ser (todo él) no deviene ("el ser es inmutable") [l'essere (l'intero) non diviene ("l'essere è immutabile")]»; el segundo, que no hay vasos comunicantes entre el ser y la nada: «el ser (todo él) ni se anula ni surge de una inicial nulidad [l'essere (l'intero) non si annulla, e non esce da una iniziale nullità]» (Severino 1981², p. 519). Pasar del olvido a la verdad del ser es la tarea ineludible de la palabra que quiere adentrarse por el sendero del Día. Y lo que la palabra que se adentra por el sendero del Día descubre es que las cosas no son nada, no pueden haber sido nada ni tampoco convertirse nunca en nada. La palabra que recorre el sendero de la Noche diferencia, como sugiere Platón, entre lo que siempre es y no deviene y lo que deviene continuamente y nunca es (Timeo 27 d-28 a), ocultando con ello lo que en la senda del Día sale a la luz: la verdad del ser, que dice que lo que es, es siempre.

Si la verdad del ser es lo inmutable, lo imperecedero, ¿cómo se muestra lo inmutable o imperecedero del ser en el lenguaje de Occidente? ¿Qué fuerza puede poner a salvo al ser? Y, todavía, ¿cómo garantizar la verdad del ser? Severino considera que la verdad es un decir que se descubre a sí mismo como aquello que no puede ser desmentido. Y no sólo es un decir, sino «un decir que muestra la propia fuerza invencible. Lo que es dicho es la verdad del ser» (Severino 19912, p. 165). La verdad es el decir incontrovertible que se impone porque lleva en sí mismo la fuerza para hacerse valer, para expulsar de sí lo que se le resiste. Como el decir que se impone y domina y que, por tanto, no queda expuesto a un posible desmentido, la verdad es, en primer lugar, lo que se dice en la episteme. Y la episteme es aquello que se pone sobre algo y que, por lo tanto, lleva en sí mismo la fuerza para hacerse valer sobre cualquier otro discurso. A diferencia de la ambigüedad que circunda a la dóxa (en donde la verdad del ser, o es silenciada o rotundamente negada), la verdad del ser se coloca en la episteme por encima de cualquier otro discurso. Porque la verdad del ser no puede ocultarse para siempre. Sólo el decir que sabe que cada ente es el actual y eterno aparecer del ser no puede ser desmentido. Este saber, sin embargo, es un saber tal, que de él brota una fuerza que lo hace invencible. «También de esta manera se le hace violencia, porque no se lo encuentra, sino que se le quiere en compañía de la verdad del ser» (Severino 19912, p. 168). Decir la 
verdad del ser es arrancar el ser a la metafísica con la violencia de la palabra. La fuerza está presente, por tanto, no sólo del lado de la senda de la Noche, sino también del lado del sendero del Día: dos sendas que quizá no sean sino dos tramos de un mismo camino.

\section{Voluntad interpretadora}

Occidente piensa el mundo como la tierra segura en donde las cosas surgen de la nada y a ella retornan. Esta evidencia es resultado de la voluntad que quiere que algo sea signo de otra cosa. La voluntad que quiere que algo sea signo de otra cosa es una voluntad que interpreta el signo como cosa y que busca, por consiguiente, equiparar palabra y cosa. La equiparación que realiza el intérprete, sin embargo, sólo es posible a condición de que se fuerce a la cosa a quedar contenida en el espacio de la palabra: «la interpretación aislante es el fundamento del dominio [l'interpretazione isolante è il fondamento del dominio]» (Severino 1980, p. 570). Nietzsche y, posteriormente, Heidegger han llamado la atención sobre los vínculos que unen el interpretar con la fuerza que el intérprete se ve obligado a desplegar en la interpretación. Si el primero afirma que la interpretación es ya un medio de enseñorearse de la cosa, Heidegger alega que para saber lo que la palabra dice, «toda interpretación (...) debe recurrir necesariamente a la fuerza $\gg^{4}$ (Heidegger 1981, p. 172). Heidegger emplea el verbo abringen para referirse a la acción que ejecuta el intérprete: el intérprete tiene que ser capaz de «arrancar» de la palabra su auténtico y oculto significado. La interpretación asténica no es posible: interpretar es penetrar en lo que ha quedado sin decir para sacarlo a la luz con violencia. Severino reconoce, asimismo, las raíces violentas de la interpretación y del lenguaje: «la voluntad de poder que aísla la tierra es voluntad interpretante, interpretación, esto es, lenguaje. El poder es inseparable del lenguaje [la volontà di potenza que isola la terra è volontà interpretante, interpretazione, cioè linguaggio. La potenza è inseparabile dal linguaggio]» (Severino 2007, p. 132). El lenguaje, como interpretación, es voluntad de dominio: al hacer de la cosa un signo, el lenguaje pone a disposición del intérprete a la cosa para producir con ella, transformar, aniquilar, etc. Porque la correspondencia entre signo y significado es fruto del acuerdo, de un consenso o

\footnotetext{
4 Cf. Nietzsche (1977, p. 489): «en verdad, la interpretación es un medio por el que se llega a dominar algo»; La interpretación y traducción por parte de Heidegger de algunos fragmentos de filósofos presocráticos es veladamente criticada por Severino. Del lenguaje de Anaximandro, Heráclito o Parménides, esto es, del ambiguo lenguaje pre-metafísico, escribe Severino que «se puede establecer la sintaxis, pero no la semántica ontológica de un lenguaje que no hace explícito el sentido del ser y de la nada» (Severino 19912, p. 161). Para una crítica pormenorizada de las traducciones de fuentes griegas por parte de Heidegger, cfr. Coppieters de Gibson (1982, pp. 53-70); Castoriadis (1978, p. 355; 1999, pp. 17-46); etc.
} 
pacto que es aceptado, no sólo por los usuarios de un lenguaje, sino también por los intérpretes del mismo. Esta convención no es algo fáctico: esclarecer los posibles sentidos que se esconden tras una palabra en la que la coordinación entre signo y significado ha quedado fijada requiere de un gran esfuerzo crítico. El esfuerzo crítico es el presupuesto del que parte el quehacer hermenéutico. La hermenéutica, que se abre al lenguaje en su relación con el todo, trata de comprender la multivocidad que resuena en la palabra. En Oltre il linguaggio Severino sostiene que las palabras de una lengua, las voces y sonidos que la conforman, son elementos lingüísticos históricamente determinados: la palabra es el aparecer la cosa en una lengua que se deja interpretar. La palabra es, por tanto, lo que aparece en el interior de la interpretación. Y es la interpretación la que ubica en la historia el elemento lingüístico en que aparece. La acción del intérprete, sin embargo, no es una acción exterior al lenguaje: es el intérprete mismo el que aparece en el núcleo de la palabra porque todo interpretar es ya un interpretar desde una palabra anterior. Severino señala que este mismo «aparecer» surge ya en el seno de las palabras que lo expresan, cuyo significado «remite a otras palabras, al infinito. La reflexión sobre la relación entre la palabra y la cosa no surge nunca de la palabra y del carácter histórico de la palabra (el cual, sin embargo, aparece en el interior de la interpretación que pone la palabra, a la que el pensamiento aparece unido como palabra histórica) [rinvia ad altre parole, all'infinito. La riflessione sul rapporto tra la parola e la cosa non esce mai dalla parola e dal carattere storico della parola (il quale, tuttavia, appare all 'interno dell'interpretazione che pone la parola, a cui il pensiero appare unito, come parola storica)]» (Severino 1992, p. 143).

Interpretar no significa fijar, decidir o establecer el valor de aquello que aparece; el valor de lo que aparece no está contenido en el interpretar, sino que es algo establecido por el intérprete. Toda interpretación se funda en convenciones. Porque nada indica que una palabra sea necesariamente el signo de otra cosa: que una cosa sea signo y que un signo sea signo de una cosa, es propio de la voluntad que se encuentra desde siempre en el lenguaje de Occidente. La voluntad asigna un significado a la cosa, y la cosa, constituida por un conjunto de determinaciones empíricas (forma, luz, movimiento, resistencia, etc.), queda fijada a un significado que le es extraño. Al fijar desde fuera el significado, la cosa queda a disposición de la voluntad del intérprete, que puede hacer con ella lo que sea. El intérprete, no obstante, debe dejarse iluminar por la cosa y protegerse contra la arbitrariedad que pueda proyectar sobre la misma. Es por esto que la hermenéutica filosófica ha puesto el acento en lo que Gadamer denomina Neu-Entwerfen, «re-proyectar» (Gadamer 1990, p. 272): huir de la arbitrariedad, del error o del malentendido en el interpretar, significa dejar a un lado las opiniones previas que determinan la comprensión del intérprete para encontrar el sentido genuino de lo interpretado. No obstante, uno entiende, comprende o se comprende desde una estructura previa -esto es, uno 
entiende, comprende o se comprende desde lo que Heidegger llama la Vor-Struktur des Verstehens, la estructura previa de la comprensión (Heidegger 1996, p. 151). Severino considera, por el contrario, que esta estructura previa se organiza a partir de las categorías de un lenguaje que es presa ya de la metafísica. Por ello la crítica del pensador italiano a la hermenéutica se sitúa en el terreno del olvido y, consecuentemente, la no verdad del ser. Tanto el intérprete como lo interpretado se mueven en este espacio común, que es el espacio de la palabra enajenada respecto de la verdad del ser. La interpretación, que en Destino della necessità es la voluntad que conduce al aislamiento de la tierra, puede llegar a transparentar la verdad del ser si consigue hablar la lengua del Día. Solamente así puede llevarse a la luz lo que es la gran mistificación de la cultura occidental: que el devenir es el salir los entes de la nada y su regreso a ella. «Sólo si el devenir es el aparecer y desaparecer de los eternos el devenir no es imposible. Lo vuelve imposible el modo en el que es pensado en Occidente, esto es, el ser pensado como oscilación de los entes entre el ser y la nada [Solo se il divenire è il comparire e scomparire degli eterni il divenire non è impossibile. Lo rende impossibile il modo in cui è pensato dall'Occidente, cioè l'essere pensato come oscillazione degli essenti tra l'essere e il nulla]» (Severio 1992, p. 27). Severino no niega el devenir -tampoco afirma que el devenir sea ilusorio o ficticio: niega la interpretación que a partir de la palabra de Parménides y Platón impone una experiencia errónea del devenir. El ente no es un oscilar entre el ser y la nada: todo ente es eterno. Los entes están desde siempre a salvo en el círculo del aparecer porque el círculo del aparecer es la estructura originaria, el trasfondo del continuo aparecer y desaparecer de los entes. Pensar que el ente es ente y es nada es resultado de la voluntad que interpreta desde la palabra cautiva de la metafísica occidental. Esta voluntad interpretadora es el fundamento de la alienación que conduce al ocaso de Occidente. ¿Es entonces el cumplimiento del declinar de Occidente el gozne sobre el que la voluntad interpretadora da su giro decisivo hacia el destino de la necesidad que dice la verdad del ser?

\section{Diálogo y violencia}

A propósito de unas declaraciones de Norberto Bobbio en las que el filósofo y politólogo italiano sostiene la incompatibilidad de la violencia y el diálogo (la primera se basa en la destrucción; la segunda, en el respeto al otro), Severino se pregunta si no será, más bien, que el diálogo y la violencia constituyen, no dos soluciones antagónicas, sino complementarias, en tanto representan dos modos de expresión de una misma esencia: «¿y si las raíces de la violencia estuviesen precisamente constituidas por el sentido que la "razón" ha asumido en la civilización occidental?» (Severino 1991, p. 174). El argumento de Severino se funda en que la propia razón es, desde la senda que abre Parménides, aquello que reúne lo que 
deviene: el continuo devenir de las cosas, el que las cosas estén a disposición del hombre porque son sustancialmente nada, es el axioma del que parte el lenguaje metafísico de Occidente. Sin embargo, es a partir de ese mismo lenguaje metafísico que la razón se presenta como negación de la violencia. Sostener que diálogo y violencia brotan de una raíz común, ¿no es afirmar que el logos del diálogo es una fuerza que trata de imponerse en el encuentro intersubjetivo del uno con el otro? «Inicialmente, el mortal domina la tierra por medio del dominio de la palabra-vozescritura y del símbolo -o sea, de las imágenes en las que se reflejan las cosas de la tierra [Inizialmente il mortale domina la terra attraverso il dominio della parolavoce-scrittura e del simbolo -ossia dell'immagine in cui si rispecchiano le cose della terra]» (Severino 1980, p. 570). El dominio humano que hace del espacio en el que habita, no la tierra segura, sino la tierra aislada del devenir, comienza con la palabra que, sobre la base de ciertas convenciones, refiere un tipo de significado a ciertas categorías semánticas más amplias. A través de la palabra el hombre se apodera de la totalidad de lo existente. ¿Por qué estimar, entonces, que la palabra que brota en el diálogo es ajena a la voluntad de dominio que guía a la razón? En este punto, el argumento de Emanuele Severino podría condensarse aludiendo a unas líneas conservadas de Empédocles. En los versos iniciales del poema Acerca de la naturaleza, califica Empédocles al ser humano de «ingenuo, ciego, insensato»

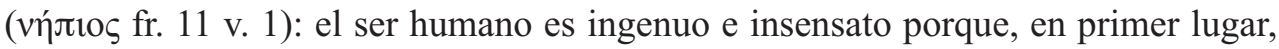
cree que lo que no ha sido deviene, llega a ser. Y llegar a ser lo que no ha sido es llegar a ser lo que era nada. De la nada, de la infinita lejanía de lo existente, ¿acaso es posible que algo llegue a ser? Pero el ser humano no sólo cree que las cosas son nada, sino que teme que algo muere y es aniquilado enteramente (fr. 11 v. 3). Es por esto que Empédocles tacha al hombre de ingenuo: porque cree, no sólo en el devenir, sino en la caducidad y destrucción de todo lo existente. La persuasión de que las cosas son aniquiladas para siempre es la extrema violencia a la que la razón somete a las cosas, «la extrema falta de respeto a su ser lo que son. Esta persuasión es la raíz oculta desde la que se desarrolla la historia de Occidente, esto es, la historia de la violencia extrema» (Severino 1991, p. 176). Si la razón desde la que se alza el diálogo es violencia (porque la razón es la convicción de que la totalidad de las cosas son nada, provienen de la nada y serán nada), el diálogo entendido como espacio de la convivencia - como la esfera del «entre» a la que se refiere Martin Buber- debe ser desenmascarado. «El diálogo entre los hombres es siempre un equívoco», escribe Severino: «el "diálogo" es la máscara de la lucha entre los hombres» (Severino 199133, p. 181). ¿Por qué máscara? ¿Por qué lucha? El diálogo es máscara porque oculta bajo la apariencia de la razón común la estructura ontológica del devenir: si la cosa es nada, la cosa puede violentarse, forzarse, aniquilarse. Pero si puede hacerse violencia a la cosa es porque la fe en el devenir se presenta junto a la fe que afirma la imposibilidad de cualquier verdad inmutable, incontro- 
vertible o indomeñable. Si nada hay definitivo, todo puede ser sobrepasado, vulnerado, violado.

En una cultura como la occidental en la que todo es circunstancial e hipotético, provisional, condicionado, relativo; una cultura que ha llevado hasta sus últimas consecuencias la lucha contra cualquier absoluto; que excluye la posibilidad de una verdad «definitiva»; en una cultura así todo puede ser sobrepasado porque no hay límite que la acción y la palabra del hombre no superen. «En una civilización que vive la carencia de la verdad aun cuando cree poseerla, cada forma práctica o teórica de existencia es una fuerza que puede imponerse sobre la forma antagonista por esta simple "razón": la de ser más fuerte [In una civiltà che vive la mancanza della verità anche quando ritiene di possederla, ogni forma pratica o teorica di esistenza è una forza, che riesce a imporsi sulle forme antagoniste per questa ultima semplice "ragione": di essere più forte]» (Severino 2010, p. 73). La misma civilización occidental que condena la fuerza y la violencia impone $s u$ fuerza y $s u$ violencia: implícita, a través de la palabra sobre la que se articulan instituciones políticas, sociales y culturales, instituciones que se ven obligadas a desplegar una fuerza todavía mayor que la que combaten (códigos, mandatos, imperativos, leyes, etc.); explícita, por medio del ejército, la policía y demás cuerpos de seguridad del Estado que, entre todos, ostentan el monopolio de la fuerza legítima. La palabra comunitaria y razonada del diálogo, entonces, además de máscara es lucha: lucha solapada entre dos formas de persuasión que, si bien no están enfrentadas directamente, son, como formas de persuasión o convicción, fuerza, potencia, voluntad de dominio.

La pulsión agonal se oculta en el diálogo bajo la apariencia de la convicción. Porque la convicción, que es hipótesis, fe, creencia, quiere imponerse como logos. Esto es, en la reciprocidad del diálogo, una de las partes quiere llevar su propio «estar persuadido» al espacio de la episteme. En un universo como el occidental en el que la acción instrumental ha llevado al hombre a la destrucción de toda necesidad, de todo orden estable y, en definitiva, de todo inmutable, la voluntad que apela a una necesidad que ella misma ha quebrado es una voluntad que hace violencia a la verdad y que, además, quiere arrogarse con su acción un sentido de la verdad espurio. La convicción no es episteme: es la fe que se alza por encima de cualesquiera otras alternativas en el momento en el que la pregunta que inicia el diálogo (y no por casualidad sitúa Elias Canetti a la pregunta entre los elementos específicos de poder) se sobrepone. «En nuestra civilización todo se ha vuelto fe: la ciencia, la moral, la política, el arte, la religión e incluso la incredulidad religiosa. En nombre del contenido de su fe, nuestra civilización condena la violencia. Pero la fe, en cuanto tal, ¿no es acaso la forma originaria de la violencia? [Nella nostra civiltà tutto è ridiventato fede: la scienza, la morale, la politica, l'arte, la religione e anche l'incredulità religiosa. In nome del contenuto della sua fede, la nostra civiltà condanna la violenza. Ma la fede, in quanto tale, non è forse la forma originaria della violenza?]» (Severino 2010, p. 70). La fe o la convicción de quien, a través de 
la palabra, quiere llegar a encontrar un remedio racional contra la violencia, se impone -sea o no consciente de ello- a las distintas alternativas que se presentan en el diálogo. Y este imponerse una convicción en el diálogo (convicción que no es todavía fuerza física), anuncia, sin embargo, que la razón dialogante, aunque pretenda lograr el consenso por medio de un discurso sin violencia, es un momento, siquiera teórico, de la misma violencia.

\section{Referencias bibliográficas}

ARISTÓTELES (1980): ПEPI EPMHNEIA . De interpretatione, Valencia, Cuadernos Teorema.

ARISTÓTELes (1998): Física, Madrid, Gredos.

Bourdieu, P. (1980): Le sens pratique, París, Minuit.

CAstoriadis, C. (1978): Les Carrefours du labyrinthe, París, Éditions du Seuil.

Castoriadis, C. (1999): Figuras de lo pensable, Madrid, Cátedra.

Coppieters de Gibson, D. (1982): «Les Grecs et la question de l'homme. A propos d'une lecture de Sophocle par Heidegger», en Qu'est ce que l'homme? Hommage à Alphonse de Waehlens, Bruselas, Publications des Facultés Universitaires Saint-Louis.

Diels, H. y Kranz, W. (1968): Die Fragmente der Vorsokratiker, Dublín-Zúrich, Weidmann.

GadAmer, H.-G. (1990): Wahrheit und Methode, en Gesammelte Werke 1. Hermeneutik I, Tubinga, J.C.B. Mohr.

HABERMAS, J. (1983): La reconstrucción del materialismo histórico, Madrid, Taurus.

HABERMAS, J. (2010): «Leadership and Leitkultur», New York Times, 28 octubre, Nueva York.

Hegel, G. W. F. (1970): Enzyklopädie der philosophischen Wissenschaften im

Grundrisse, en Werke, tomo 8, Frankfurt, Suhrkamp.

HeIDEgGer, M. (1996): Sein und Zeit, Tubinga, Max Niemeyer.

HeidegGer, M. (1981): Kant y el problema de la metafísica, México, Fondo de Cultura Económica.

HobBes, T. (1989): Leviatán. La materia, forma y poder de un Estado eclesiástico y civil, Madrid, Alianza.

KanT, I. (1998): Kritik der reinen Vernunft (ed. J. Timmermann), Hamburgo, Felix Meiner.

NietzSChe, F. (1977): Aus dem Nachlab der Achtzigerjahre, en Werke (ed. K.

Schlechta), vol. III, Múnich, Carl Hanser.

Platón (1988): Parménides, Sofista, Político, en Diálogos V, Madrid, Gredos.

Platón (1992): Crátilo, en Diálogos II, Madrid, Gredos.

Platón (1992): Filebo, Timeo, en Diálogos VI, Madrid, Gredos. 
Proclo (1999): Lecturas del Crátilo de Platón (ed. J. Ma Álvarez, A. Gabilondo, J. M. García), Madrid, Akal.

Schmitt, C. (1991): El concepto de lo político, Madrid, Alianza Universidad.

SeEsslen, G. (2010): «Die Arroganz der Macht», Die Tageszeitung, 15 noviembre, Berlín.

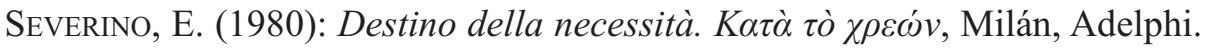

SEVErino, E. (1981): Gli abitatori del tempo. Cristianesimo, marxismo, tecnica, Roma, Editore Armando Armando.

SEVERINO, E. (19812): La struttura originaria, Milán, Adelphi.

SEVERINo, E. (1991): El parricidio fallido, Barcelona, Destino.

SEVERINO, E. (19912): Esencia del nihilismo, Madrid, Taurus.

SEVErino, E. (19913): La tendencia fundamental de nuestro tiempo, Pamplona, Pamiela.

SEVErino, E. (1992): Oltre il linguaggio, Milán, Adelphi.

SEverino, E. (2000): "Pensiero greco e scienza moderna. Discussione con H. G. Gadamer", en La legna e la cenere. Discussioni sul significato dell'esistenza, Milán, Rizzoli.

SEverino, E. (2006): La follia dell'angelo (ed. I. Testoni), Milán, Mimesis.

SEVERINO, E. (2007): Oltrepassare, Milán, Adelphi.

SEVERINO, E. (2010): TÉCHNE. Le radici della violenza, Milán, Bur-Rizzoli.

SpInOzA, B. (1882): Tractatus Theologico-Politicus, en Benedicti de Spinoza Opera (ed. Vloten, J. van y Land, J. P. N.), vol. I, La Haya, M. Nijhoff.

WEBER, M. (1996): El político y el científico, Madrid, Alianza.

Vicente Ordóñez Roig

Universidad Jaime I

Facultad de Humanidades

vordonez@fis.uji.es 